CLINICAL STUDY

\title{
Pituitary apoplexy: re-evaluation of risk factors for bleeding into pituitary adenomas and impact on outcome
}

\author{
Diane L Möller-Goede ${ }^{1,2}$, Michael Brändle ${ }^{2}$, Klara Landau ${ }^{3}$, Rene L Bernays ${ }^{4}$ and Christoph Schmid ${ }^{1}$ \\ ${ }^{1}$ Division of Endocrinology and Diabetes, Department of Internal Medicine, University Hospital Zurich, 8091 Zurich, Switzerland, ${ }^{2}$ Division of \\ Endocrinology and Diabetes, Department of Internal Medicine, Cantonal Hospital of St Gallen, 9007 St Gallen, Switzerland, ${ }^{3}$ Department of \\ Ophthalmology and ${ }^{4}$ Department of Neurosurgery, University Hospital Zurich, 8091 Zurich, Switzerland \\ (Correspondence should be addressed to D L Möller-Goede at Division of Endocrinology and Diabetes, Department of Internal Medicine, Cantonal Hospital of \\ St Gallen; Email: diane.moeller@planconsulte.ch)
}

\begin{abstract}
Objective: To assess frequency, symptoms and outcome of pituitary apoplexy (PA) among pituitary adenoma patients, to gain better insight into risk factors for bleeding into pituitary adenoma and to estimate the sequelae of PA by means of a matched control group.

Method: By reviewing charts of 574 patients with pituitary adenoma, we analysed incidence, symptoms and outcome of PA and potential risk factors for developing PA by means of a control group (patients with pituitary adenoma without PA).

Results: In total, 42 suffered from PA, all had macroadenomas; 30/217 male (14\%) and 12/179 female (7\%) macroadenoma patients, 32/194 patients with clinically non-functioning (16.5\%) and 10/202 with clinically active $(5.0 \%)$ macroadenoma were affected. Antithrombotic therapy predisposed patients to PA $(P=0.026)$, diabetes mellitus and hypertension did not $(P=1.00)$. Patients with PA and pituitary adenoma patients without PA had similar frequencies of hypopituitarism (45 vs $48 \%$, $P>0.05$ ) and visual field defects (38 vs 55\%, P>0.05), but ophthalmoplegia was significantly more common ( 76 vs $5 \%, P<0.001)$ in patients with PA. Nearly all patients were treated by surgery; most recovered from ophthalmoplegia, whereas visual function improved only moderately. Endocrine outcome was worse in patients with PA than in patients without PA.

Conclusions: Male sex and characteristics of the adenoma itself (especially tumour size and tumour type) rather than patient's cardiovascular risk factors such as diabetes and hypertension seem to predispose to PA; antithrombotic therapy may also be important.
\end{abstract}

European Journal of Endocrinology 164 37-43

\section{Introduction}

Pituitary apoplexy (PA) is defined as an acute clinical syndrome characterised by sudden onset of headaches, visual impairment and ophthalmoplegia due to haemorrhage with enlargement of a pituitary adenoma (1). The majority of reports on PA consist of single cases or small case series describing this clinically impressive condition; most of these reports, however, do not allow more rigorous data analysis including statistical evaluation. We found 11 retrospective studies in the last 29 years with a large number of patients with PA $(\geq 16)(1-11)$. The results and essential information of these studies are summarised in Table 1 . To the best of our knowledge, there are no previous case-control studies comparing potential risk factors, symptoms and outcome of patients with PA and pituitary adenoma patients without PA.

The aims of our study were to assess frequency, symptoms and outcome of PA among pituitary adenoma patients and to analyse potential risk factors for developing PA by means of a matched control group. Knowledge and information about potential risk factors could help to prevent PA in pituitary adenoma (and incidentaloma) patients with risk factors by providing an early indication for surgery.

\section{Subjects and methods}

We performed a retrospective chart review of patients with pituitary adenoma presenting to the Division of Endocrinology, Department of Internal Medicine, University Hospital of Zurich. Patients were identified by a search in the electronic database of our division with the following keywords: pituitary adenoma, pituitary tumour, hypopituitarism, prolactinoma, acromegaly and Cushing's disease.

Charts of 574 pituitary adenoma patients from 1980 to November 2007 were reviewed. Patients who suffered an apoplexy in their pituitary adenoma were identified. We diagnosed PA according to the clinical 
Table 1 Summary of previous large retrospective studies about pituitary apoplexy

\begin{tabular}{|c|c|c|c|c|}
\hline \multirow[b]{2}{*}{ Study } & \multirow{2}{*}{$\begin{array}{l}\text { Total number } \\
\text { of patients }\end{array}$} & \multicolumn{2}{|c|}{ Incidence of PA } & \multirow[b]{2}{*}{ Essential information } \\
\hline & & $n$ & $\%$ & \\
\hline (1) & 560 & 51 & 9.1 & $\begin{array}{l}\text { PA is not correlated with sex, endocrine function or histological type of the adenoma, but } \\
\text { with age }\end{array}$ \\
\hline (2) & & 37 & & $\begin{array}{l}\text { In stable patients with PA, surgical decompression should be performed as soon as } \\
\text { possible, because delays beyond } 1 \text { week may retard the return of visual function }\end{array}$ \\
\hline (3) & 799 & 39 & 4.9 & $\begin{array}{l}\text { Authors suggest surgical treatment in every case of PA to enhance neurological and } \\
\text { endocrine recovery }\end{array}$ \\
\hline$(4)$ & 125 & 16 & 12.8 & $\begin{array}{l}\text { In PA, surgical treatment was associated with better outcome than treatment with } \\
\text { dexamethasone }\end{array}$ \\
\hline (5) & 982 & 35 & 3.2 & $\begin{array}{l}\text { Hypertension may be an important predisposing factor for PA. Transsphenoidal surgery } \\
\text { is safe and effective. It is indicated if there are associated abnormalities of visual } \\
\text { acuity or visual fields }\end{array}$ \\
\hline$(6)$ & & 45 & & $\begin{array}{l}\text { Patients with classical PA and without any or only with mild, non-progressive } \\
\text { neuroophthalmic signs can be managed conservatively in the acute stage }\end{array}$ \\
\hline$(7)^{\mathrm{a}}$ & 721 & 27 & 3.7 & $\begin{array}{l}\text { Anterior pituitary function was more frequently preserved, normalised or even improved } \\
\text { after transsphenoidal surgery compared with transcranial surgery in patients with non- } \\
\text { functioning pituitary adenomas }\end{array}$ \\
\hline (8) & & 62 & & $\begin{array}{l}\text { Emergency surgery is required in patients with a diminished level of consciousness, } \\
\text { deteriorating vision or sudden onset of blindness. Isolated cranial nerve palsies may } \\
\text { be successfully managed conservatively }\end{array}$ \\
\hline$(9)^{a}$ & 192 & 41 & 21 & $\begin{array}{l}\text { PA occurs more frequently than usually assumed. In patients operated on for non- } \\
\text { functioning pituitary adenoma, survival is independent of the occurrence of PA }\end{array}$ \\
\hline$(10)$ & 1540 & 24 & 1.6 & $\begin{array}{l}\text { PA is a rare event. Complete recovery is possible if the diagnosis is rapidly obtained and } \\
\text { adequate management is initiated in time. Surgical results are very satisfactory in the } \\
\text { majority of cases }\end{array}$ \\
\hline$(11)$ & 262 & 25 & 9.5 & $\begin{array}{l}\text { Classical PA is a rare event. The incidence of subclinical PA is higher than classical PA. } \\
\text { Patients with classical PA have a higher mean age, and most patients were male } \\
(68 \%) \text {. Visual improvement is better in subclinical PA than in classical PA. In both } \\
\text { classical and subclinical PA, anterior pituitary function is able to recover }\end{array}$ \\
\hline
\end{tabular}

${ }^{\mathrm{a}}$ In these studies only patients with non-functioning pituitary adenomas were included.

definition of Randeva et al. (5): presence of a pituitary adenoma together with at least one of the following criteria: episode of acute severe headaches and sudden visual disturbance such as visual field defects or ophthalmoplegia.

Patients with PA were compared with the total cohort of patients with pituitary adenoma during the same period. To analyse potential risk factors or associated factors for PA and to estimate the sequelae of PA, we compared PA patients with a control group (matched case-control study design). The control group was formed as follows: we assigned to each PA patient two pituitary adenoma patients without PA, who were matched for sex, tumour type, tumour size and age (downward order of relevance). For additional risk factors (i.e. oestrogens, antithrombotic therapy, diabetes mellitus, arterial hypertension, bilateral adrenalectomy, cardiac surgery and therapy with dopamine agonists) and outcome, we compared the PA patients with the control group $(5,12,13)$.

All patients underwent computed tomography (CT) scan and/or magnetic resonance imaging (MRI) of the sellar region. In the PA group, 11 patients $(26 \%)$ had a CT, 23 patients $(55 \%)$ had an MRI, and 8 patients $(19 \%)$ had both. In the control group, 26 patients (31\%) had a CT, 43 patients (51\%) had an MRI, and 15 patients (18\%) had both. Tumours measuring $<1 \mathrm{~cm}$ in diameter (as determined by neuroimaging) were classified as microadenomas and larger tumours as macroadenomas. Tumour type was mostly determined on histology, but sometimes histological analysis only showed necrosis. In these cases, tumour type was defined by clinical presentation and endocrine studies at diagnosis. Clinical presentation of gonadotrophinsecreting tumours is similar to that of clinically nonfunctioning tumours. Therefore, these tumours were included under the term of clinically non-functioning tumours. Tumours with no further characteristics or endocrine activity were assigned to that group, too. Endocrine function was evaluated at the time of admittance to the hospital (before medical and surgical treatment), as well as 12 months after surgery. Secondary adrenal failure was defined by the perceived need for glucocorticoid replacement therapy with concomitant low (in the majority $<200 \mathrm{nmol} / \mathrm{l}$ ) serum cortisol levels in the early morning. Secondary hypothyroidism was defined by repeatedly low (usually $<10 \mathrm{pmol} / \mathrm{l}$ ) serum-free thyroxine levels recorded previously. We defined male hypogonadism as having low serum testosterone (usually $<12 \mathrm{nmol} / \mathrm{l}$ ) and gonadotrophin levels (usually FSH and LH both $<2 \mathrm{mU} / \mathrm{ml}$ ), and female hypogonadism as having amenorrhoea and low oestradiol (usually $<70 \mathrm{pmol} / \mathrm{l}$ ) without rising gonadotrophin levels (usually FSH and LH both $<5 \mathrm{mU} / \mathrm{ml}$ ). 
Table 2 Tumour type.

\begin{tabular}{|c|c|c|c|c|c|c|}
\hline \multirow{2}{*}{$\begin{array}{l}\text { Macroadenoma } \\
\text { patients }\end{array}$} & \multicolumn{2}{|c|}{ With PA } & \multicolumn{2}{|c|}{ Without PA } & \multicolumn{2}{|c|}{ Total } \\
\hline & $n$ & $\%$ & $n$ & $\%$ & $n$ & $\%$ \\
\hline Total & 42 & 100 & 354 & 100 & 396 & 100 \\
\hline Men & 30 & 71 & 187 & 53 & 217 & 55 \\
\hline Women & 12 & 29 & 167 & 47 & 179 & 45 \\
\hline Non-functioning & 32 & 76 & 162 & 45 & 194 & 49 \\
\hline Prolactinoma & 7 & 17 & 119 & 34 & 126 & 32 \\
\hline $\mathrm{GH}$-secreting & 1 & 2 & 62 & 18 & 63 & 16 \\
\hline Cushing's disease & 1 & 2 & 10 & 3 & 11 & 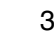 \\
\hline Nelson's syndrome & 1 & 2 & 1 & 1 & 2 & 1 \\
\hline
\end{tabular}

Median and range were used for descriptive statistics. Fisher's exact test was used to analyse categorical variables and groups. The McNemar test was used to analyse differences in categorical variables within the group (14). Multivariate logistic regression analyses adjusting for age, sex and tumour size were conducted with the whole group. A $P$ value of $<0.05$ was considered statistically significant. All statistical analyses were performed using SPSS version 16.0 (SPSS Inc., Chicago, IL, USA).

\section{Results}

Of the 574 patients, $42(7.3 \%)$ with pituitary adenoma fulfilled the diagnostic criteria for classical PA as defined above. In 41 of the 42 patients with classical PA, pituitary adenoma had been unknown before PA occurred. The median age of the PA patients was 53.5 (range 21-85) years. The median age of the control group was 50.0 (range 23-84) years.

\section{Tumour size}

All 42 patients with PA had a macroadenoma; 354 patients $(67 \%)$ without PA had a macroadenoma, 160 (30\%) had a microadenoma and 18 (3\%) had an adenoma of unknown size.

\section{Sex}

Although women $(317 ; 55 \%)$ presented overall more frequently with pituitary adenoma than men (257; $45 \%)$, PA occurred about three times more often in men $(30 / 257$ men; $12 \%)$ than in women $(12 / 317$ women; $4 \%$ ) (odds ratio $=3.36, \mathrm{CI}=1.68-6.71, P<0.001$ ). Since PA occurred only in macroadenomas, the analysis was performed only in macroadenoma patients. Men with macroadenoma had a significantly increased risk for PA compared with women (30/217 men (14\%) and $12 / 179$ women $(7 \%)$ with PA; odds ratio $=2.23$, $\mathrm{CI}=1.11-4.50, P=0.022$; Table 2).

\section{Tumour type}

The most frequent types of pituitary macroadenoma were clinically non-functioning tumours $(49 \%)$ and prolactinomas $(32 \%)$, followed by GH-secreting tumours (16\%). Cushing's disease (3\%) and Nelson's syndrome $(0.5 \%)$ were quite rare (Table 2$)$.

Most of the PA patients had clinically non-functioning tumours. Of 194 patients, 32 (16.5\%) patients with clinically non-functioning adenoma and of 202 patients, $10(5.0 \%)$ patients with clinically active macroadenoma developed PA, resulting in a significantly higher risk for PA in clinically non-functioning macroadenomas (odds ratio $=3.79, \mathrm{CI}=1.81-7.95$, $P<0.001$ ).

Male sex and clinically non-functioning tumour type were found to be independent risk factors for PA $(P<0.001)$.

\section{Predisposing factors}

We compared the frequencies of potential risk factors (i.e. oestrogens, antithrombotic therapy, diabetes mellitus, arterial hypertension, bilateral adrenalectomy, cardiac surgery and therapy with dopamine agonists) between the PA patients and the control group of matched patients with pituitary adenomas (Table 3) $(5,12,13)$. Sex, age, tumour size and tumour type (matched parameters) revealed no significant difference between PA patients and the control group.

Risk for PA was significantly elevated in patients with antithrombotic drugs (vitamin $\mathrm{K}$ antagonist or platelet inhibitors) (odds ratio $=2.96, \mathrm{CI}=1.16-7.58$, $P=0.026$ ), but not in patients with cardiovascular risk factors such as diabetes mellitus (odds ratio $=1.00$, $\mathrm{CI}=0.28-3.53, \quad P=1.00)$ and arterial hypertension (odds ratio $=0.93, \mathrm{CI}=0.38-2.29, P=1.00$ ).

Remarkably none of the 42 PA patients, but 11 of the 84 control patients, received dopamine agonist treatment, suggesting that treatment with dopamine

Table 3 Predisposing factors for PA.

\begin{tabular}{|c|c|c|c|c|c|}
\hline \multirow[b]{2}{*}{ Factors } & \multicolumn{2}{|c|}{$\begin{array}{l}\text { With PA } \\
(n=42)\end{array}$} & \multicolumn{2}{|c|}{$\begin{array}{l}\text { Control } \\
\text { group } \\
(n=84)\end{array}$} & \multirow[b]{2}{*}{$\boldsymbol{P}$ value $^{\mathrm{a}}$} \\
\hline & $n$ & $\%$ & $n$ & $\%$ & \\
\hline Antithrombotic therapy & 12 & 29 & 10 & 12 & 0.026 \\
\hline Diabetes mellitus & 4 & 10 & 8 & 10 & 1.00 \\
\hline Arterial hypertension & 9 & 21 & 19 & 23 & 1.00 \\
\hline Dopamine agonists & 0 & 0 & 11 & 13 & - \\
\hline $\begin{array}{l}\text { Oestrogens } \\
\text { (depot injection) }^{\mathrm{b}}\end{array}$ & 2 & 100 & 0 & 0 & - \\
\hline Bilateral adrenalectomy & 1 & 2 & 0 & 0 & - \\
\hline Cardiac surgery & 1 & 2 & 0 & 0 & - \\
\hline Head trauma & 3 & 7 & 0 & 0 & - \\
\hline
\end{tabular}

aStatistical analysis done by Fisher's exact test.

${ }^{\mathrm{b}}$ These calculations include only women with macroprolactinoma ( $n=2$ and 4 respectively). 
Table 4 Symptoms at presentation.

\begin{tabular}{|c|c|c|c|c|c|}
\hline \multirow[b]{2}{*}{ Symptoms } & \multicolumn{2}{|c|}{$\begin{array}{c}\text { With PA } \\
(n=42)\end{array}$} & \multicolumn{2}{|c|}{$\begin{array}{c}\text { Control } \\
\text { group } \\
(n=84)\end{array}$} & \multirow[b]{2}{*}{$P$ value $^{\text {a }}$} \\
\hline & $n$ & $\%$ & $n$ & $\%$ & \\
\hline Ophthalmoplegia & 32 & 76 & 4 & 5 & $<0.001$ \\
\hline Visual field defects & 16 & 38 & 46 & 55 & 0.091 \\
\hline Chronic headaches & 5 & 12 & 20 & 24 & 0.156 \\
\hline Amenorrhoea ${ }^{\mathrm{b}}$ & 6 & 50 & 9 & 38 & 0.499 \\
\hline Galactorrhoea $^{\mathrm{b}}$ & 2 & 17 & 4 & 17 & 1.00 \\
\hline Hypopituitarism & 19 & 45 & 40 & 48 & 0.851 \\
\hline
\end{tabular}

${ }^{\text {a }}$ Statistical analysis done by Fisher's exact test.

${ }^{\mathrm{b}}$ These calculations include only women ( $n=12$ or 24 respectively).

agonists could be protective. Oestrogen treatment tended to be a risk factor in female patients with macroprolactinoma $(n=2$ in the PA group and $n=4$ in the control group), but for this potential risk factor statistical analysis was not performed due to small sample size.

\section{Symptoms}

Symptoms at presentation are listed in Table 4. Ophthalmoplegia was significantly more frequent in the PA group than in the control group (odds ratio= 64.0, $C I=18.71-218.93, P<0.001)$. Visual field defects due to chiasma compression were slightly more frequent in the control group, but this result did not reach significance.

\section{Pituitary function}

At presentation, $45 \%$ of patients with PA and $48 \%$ of the control group were suffering from hypopituitarism such as secondary adrenal failure (7 vs 10\%), secondary hypothyroidism (14 vs 15\%) and hypogonadism (43 vs $48 \%$ ).

\section{Outcome}

Of the 42 patients with PA and 84 control patients 39 and 81 were treated by surgery respectively. Two PA patients were not operated on their pituitary lesion due to their poor general condition. One of them died 77 days after diagnosis. In a third patient, PA was not diagnosed until 40 days after the event at which stage surgery was postponed. In two control patients with macroprolactinoma, treatment with dopamine agonists was initiated and surgery became unnecessary. One control patient with an endocrine inactive macroincidentaloma refused surgery.

Patients with ophthalmoplegia recovered better from their visual disturbances than patients with visual field defects. Nearly all patients (33/36) recovered from ophthalmoplegia without sequelae, whereas visual field defects persisted in about $24 \%$ of patients $(15 / 62)$, both in the PA and the control group (Table 5). Endocrine outcome was worse in patients with PA than in the control group. The frequency of hypopituitarism increased (from 45 at presentation to $71 \%$ during follow-up, odds ratio $=4.7, \mathrm{CI}=1.30-25.33, P=0.013$ ) in the PA group, while it did not change in the control group (from 48 at presentation to $55 \%$ during follow-up, odds ratio $=1.5, \mathrm{CI}=0.68-3.41, P=0.362$; Table 5). Secondary adrenal failure and secondary hypothyroidism increased in the PA group (from 7 to $55 \%$ and from 14 to $52 \%$ ) as well as in the control group (from 10 to $33 \%$ and from 15 to $44 \%$, both $P<0.001$; Table 5).

\section{Discussion}

In our retrospective study, $7.3 \%$ of patients with pituitary adenoma presented with PA. In previous studies, the incidence of PA in patients with all kinds of pituitary adenoma amounted to $1.6-12.8 \%(1,3-5,10,11)$.

In contrast to some case reports demonstrating that PA may also occur in small pituitary tumours,

Table 5 Visual and endocrine outcome.

\begin{tabular}{|c|c|c|c|c|c|c|c|c|c|c|c|c|}
\hline \multirow[b]{3}{*}{ Condition } & \multicolumn{5}{|c|}{ With PA $(n=42)$} & \multicolumn{5}{|c|}{ Control group $(n=84)$} & \multicolumn{2}{|c|}{$\begin{array}{l}\text { PA vs Cont. } \\
\quad(P \text { value })^{\mathrm{a}}\end{array}$} \\
\hline & \multicolumn{2}{|c|}{$\mathrm{P}$} & \multicolumn{2}{|c|}{$\mathrm{O}$} & \multirow{2}{*}{$\begin{array}{c}\mathrm{P} \text { vs } \mathrm{O} \\
(P \text { value })^{\mathrm{b}}\end{array}$} & \multicolumn{2}{|c|}{$\mathrm{P}$} & \multicolumn{2}{|c|}{$\mathrm{O}$} & \multirow{2}{*}{$\begin{array}{c}\mathrm{P} \text { vs } \mathrm{O} \\
(P \text { value })^{\mathrm{b}}\end{array}$} & \multirow[t]{2}{*}{$\mathrm{P}$} & \multirow[t]{2}{*}{$\mathrm{O}$} \\
\hline & $n$ & $\%$ & $n$ & $\%$ & & $n$ & $\%$ & $n$ & $\%$ & & & \\
\hline Ophthalmoplegia & 32 & 76 & 3 & 7 & NA & 4 & 5 & 0 & 0 & NA & $<0.001$ & - \\
\hline Visual field defects & 16 & 38 & 2 & 5 & NA & 46 & 55 & 13 & 15 & NA & 0.091 & 0.142 \\
\hline Hypopituitarism $^{c}$ & 19 & 45 & 30 & 71 & 0.013 & 40 & 48 & 46 & 55 & 0.362 & 0.851 & 0.084 \\
\hline $\begin{array}{l}\text { Secondary adrenal } \\
\text { failure }\end{array}$ & 3 & 7 & 23 & 55 & NA & 8 & 10 & 28 & 33 & $<0.001$ & 0.750 & 0.034 \\
\hline Hypogonadism & 18 & 43 & 23 & 55 & 0.332 & 40 & 48 & 39 & 46 & 1.000 & 0.705 & 0.451 \\
\hline Hypothyroidism & 6 & 14 & 22 & 52 & NA & 13 & 15 & 37 & 44 & $<0.001$ & 1.000 & 0.450 \\
\hline Diabetes insipidus & 1 & 2 & 1 & 2 & NA & 0 & 0 & 8 & 10 & NA & - & 0.270 \\
\hline
\end{tabular}

$\mathrm{P}$, at presentation; O, outcome; Cont., control; NA, not applicable.

aStatistical analysis done by Fisher's exact test.

${ }^{\mathrm{b}}$ Statistical analysis done by the McNemar test.

'The term 'hypopituitarism' includes any (including partial) pituitary failure such as ACTH, TSH or gonadotrophin deficiency. 
we postulate that a large tumour size is associated with a significantly increased risk for PA, because all our patients with PA had a pituitary macroadenoma $(13,15)$. This finding is in line with the study of da Motta et al. (4), in which all patients had a pituitary tumour with important suprasellar extension. An additional major risk factor in our study was male sex. Men suffered significantly more frequently from PA than women, irrespective of tumour size. Some, but not all studies, report that male sex is an independent risk factor for PA $(1,4,5,8,11-13,16,17)$. Yet another major risk factor represents tumour type. In agreement with some but not all previously published studies, the incidence of PA was significantly higher in our patients with clinically non-functioning tumours $(1,2,4-6,8$, 11, 12). Wakai et al. (1) did not find a significant difference in the incidence of PA among different tumour types in their study of 560 pituitary adenoma patients and 51 PA patients. However, da Motta et al., Randeva et al., Sibal et al. and Semple et al. $(4-6,8)$ reported an increased risk for PA in clinically non-functioning tumours (between 60 and 77\%).

Mechanisms for the development of PA are not fully understood. As discussed by Bjerre et al. (18), blood supply to the anterior pituitary lobe is provided by portal vessels through the infundibulum. As the perfusion pressure is very low in these portal vessels, pituitary adenomas are particularly susceptible to even minor increments in intrasellar pressure caused by a tumour (18). Beside an elevated intrasellar pressure, a further important factor for developing PA could be the degree and type of vascularisation of the tumour. Some authors suggest that pituitary adenomas can outgrow their blood supply resulting in ischaemic necrosis followed by haemorrhage $(5,8)$. Cardoso \& Petersen (17) have postulated that an intrinsic vasculopathy in pituitary adenomas renders them more susceptible to infarction and haemorrhage. McCabe et al. (19) found a markedly raised vascular endothelial growth factor (VEGF) mRNA expression in the tissue of clinically nonfunctioning tumours compared with other types of pituitary tumours and normal pituitaries, which could indicate that angiogenesis may be different, and that properties of tumour vessels could contribute to an increased risk for PA in clinically non-functioning tumours. The results of these studies, including ours, are consistent with proposed theories on the pathogenesis of PA: beside male sex, large tumours and nonfunctioning tumour type are major risk factors for development of PA.

In addition to these three major risk factors, other potential risk factors have been discussed in the literature: arterial hypertension, sudden changes in arterial blood pressure, diabetes mellitus, head trauma, transient elevations of intracranial pressure, cardiac surgery, dynamic tests of pituitary function with releasing factors, antithrombotic therapy, oestrogens, dopamine agonists, somatostatin analogues and radiotherapy $(5,12,13)$. Of these risk factors, we could confirm antithrombotic therapy (vitamin K antagonist or platelet inhibitors) as significant in our study.

Suffering a head trauma may also be associated with an elevated risk for PA, but because of its rare occurrence (three in the PA group and none in the control group), statistical analysis was not undertaken. The mechanism of post-traumatic PA is not yet fully understood. Bao et al. (20) speculate that the change in blood flow in pituitary adenomas due to fluctuations of intracranial pressure and blood pressure following severe head injury leads to the apoplectic event in a pituitary adenoma.

Similarly, statistical analysis was not possible for oestrogen treatment in female patients with prolactinoma due to the small sample size. Oestrogens may enhance growth and activity of prolactinoma cells, may increase perfusion demand and stimulate tumour vascularisation. Furthermore, oestrogen treatment was reported to stimulate the production of VEGF in cells isolated from prolactinoma (21).

Treatment with dopamine agonists in prolactinoma patients, by contrast, did not appear to be harmful in our study. Given that these agents decrease growth and activity of prolactinoma cells, we suggest that dopamine agonist treatment should no longer be included in the list of risk factors for PA, despite previous case reports suggesting the opposite $(3,12)$.

Diabetes mellitus and arterial hypertension were not found to be significant risk factors for PA in our study suggesting that the overall cardiovascular risk profile (which predicts stroke) does not predict bleeding into a pituitary adenoma.

Few studies address the long-term outcome of patients with PA. In our study, most patients recovered from ophthalmoplegia, whereas outcome in patients with visual field defects was worse. Since the three ocular motor cranial nerves (III, IV and VI) are peripheral nerves, they can undergo regeneration. The optic nerve as part of the white matter cannot recover after axonal disruption. In the studies by Bills et al. and Onesti et al. $(2,22)$, visual outcome was also better in patients with ophthalmoplegia than in those with visual field defects.

Concerning the endocrine outcome, an event of PA may lead to irreversible loss of pituitary cells, thus leaving the majority of our PA patients with (at least partial) pituitary insufficiency. These observations are in line with some other studies $(10,23)$. Zayour et al. (23) speculate that the rapid increase in intrasellar contents after haemorrhagic infarction of a pituitary adenoma may lead to a sudden increase in intrasellar pressure, resulting in ischaemic necrosis of the anterior pituitary and limiting the potential for functional recovery after decompression. However, Liu et al. (11) have found that some recovery of hormone deficiencies in their PA patients occurred following surgery. 
With increasing use of CT scans and MRI studies, incidentally discovered pituitary adenomas become more frequent. Most pituitary adenoma patients are assigned for treatment, especially when a clinically active adenoma or threatening visual field defects by a large macroadenoma is found. Based on our findings, we cannot comment on the best management of such patients, but our observations may be helpful in management decisions for patients with pituitary macroincidentalomas. According to our results, the threat of bleeding is highest in large, clinically nonfunctioning tumours in patients who are taking antithrombotic therapy for prevention or treatment of atherosclerosis and its complications. Therefore, among patients with pituitary incidentaloma, we would propose to treat those with macroadenoma and atherosclerosis by surgery even if there are no tumour-related signs and symptoms, to prevent PA.

Pituitary adenomas are rarely known at the time of presentation of PA; it is therefore not surprising that all epidemiological data on PA derive from retrospective studies with their obvious drawbacks. Apart from being retrospective, another limitation of our study is its long period of time. The quality of documentation of some elder cases was variable, and although neuroimaging by MRI or CT scan was performed in all patients, the exact tumour size and tumour infiltration were not always described in sufficient detail. Some tumours were possibly overestimated in size because of bleeding. However, in 36 of our $42 \mathrm{PA}$ patients (86\%), suprasellar and/or parasellar extensions were documented by brain imaging studies. Among the remaining six PA patients, four had a tumour diameter of $2 \mathrm{~cm}$ and only two had too fragmentary data about tumour dimensions. Therefore, we feel confident that the vast majority of our PA patients had macroadenomas before the event of PA. Without precise assessment of the tumour size in all patients, it was not possible to prove whether large tumour size and non-functioning tumour type were independent risk factors for PA. It can be argued that non-functioning tumours may be diagnosed at a later stage of disease due to late compression symptoms caused only by large tumours. Unfortunately, as long as we have only crude figures about tumour size (i.e. tumour size $<1 \mathrm{~cm}$ or more than $1 \mathrm{~cm}$ ) in some of the patients, we are unable to further determine any independency between these two risk factors. Moreover, concerning the endocrine status of the patients, we had only limited data on insulin hypoglycaemia stress tests, considered as gold standard for the determination of secondary adrenal failure. However, serum basal cortisol levels in the early morning may be used as first-line test in the assessment of the hypothalamicpituitary-adrenal axis both preoperatively and postoperatively, as well (24).

The strengths of our study are both the large number of included patients and the matched case-control study design comparing patients suffering from PA with a group of patients having comparable tumours without PA from the same institution and time period.

We conclude that the risk for PA depends mainly on properties of the tumour itself (tumour size and type) and on the patient's sex. Antithrombotic therapy and possibly also head trauma and oestrogen treatment in patients with prolactinoma may enhance or trigger such an event. Over the following months, most patients recovered from ophthalmoplegia but few from pituitary failure. Early diagnosis of partial pituitary failure by careful history and examination may help to discover pituitary adenoma in some - especially male - patients at an earlier stage and thus reduce the risk for PA.

\section{Declaration of interest}

The authors declare that there is no conflict of interest that could be perceived as prejudicing the impartiality of the research reported.

\section{Funding}

This research did not receive any specific grant from any funding agency in the public, commercial or not-for-profit sector.

\section{Author contribution statement}

D L Möller-Goede wrote the manuscript and was responsible for data collection. C Schmid, M Brändle and K Landau revised the manuscript. M Brändle and D L Möller-Goede calculated the statistics. $\mathrm{K}$ Landau made most of the ophthalmological examinations and R L Bernays performed most of the surgeries. All the authors contributed to the quality of this manuscript by helpful critical review of the results and the discussion.

\section{References}

1 Wakai S, Fukushima T, Teramoto A \& Sano K. Pituitary apoplexy: its incidence and clinical significance. Journal of Neurosurgery 1981 55 187-193. (doi:10.3171/jns.1981.55.2.0187)

2 Bills DC, Meyer FB, Laws ER Jr, Davis DH, Ebersold MJ, Scheithauer BW, Ilstrup DM \& Abboud CF. A retrospective analysis of pituitary apoplexy. Neurosurgery 199333 602-608. (doi:10. 1227/00006123-199310000-00007)

3 Bonicki W, Kasperlik-Zaluska A, Koszewski W, Zgliczynski W \& Wislawski J. Pituitary apoplexy: endocrine, surgical and oncological emergency. Incidence, clinical course and treatment with reference to 799 cases of pituitary adenomas. Acta Neurochirurgica 1993120 118-122. (doi:10.1007/BF02112028)

4 da Motta LA, de Mello PA, de Lacerda CM, Neto AP, da Motta LD \& Filho MF. Pituitary apoplexy. Clinical course, endocrine evaluations and treatment analysis. Journal of Neurosurgical Sciences $19994325-36$.

5 Randeva HS, Schoebel J, Byrne J, Esiri M, Adams CB \& Wass JA. Classical pituitary apoplexy: clinical features, management and outcome. Clinical Endocrinology 199951 181-188. (doi:10.1046/ j.1365-2265.1999.00754.x)

6 Sibal L, Ball SG, Connolly V, James RA, Kane P. Kelly WF, KendallTaylor P, Mathias D, Perros P, Quinton R \& Vaidya B. Pituitary apoplexy: a review of clinical presentation, management and outcome in 45 cases. Pituitary 20047 157-163. (doi:10.1007/ s11102-005-1050-3)

7 Nomikos P, Ladar C, Fahlbusch R \& Buchfelder M. Impact of primary surgery on pituitary function in patients with 
non-functioning pituitary adenomas - a study on 721 patients. Acta Neurochirurgica 2004146 27-35. (doi:10.1007/s00701003-0174-3)

8 Semple PL, Webb MK, de Villiers JC \& Laws ER Jr. Pituitary apoplexy. Neurosurgery 200556 65-72 (discussion 72-73).

9 Nielsen EH, Lindholm J, Bjerre P, Christiansen JS, Hagen C, Juul S, Jorgensen J, Kruse A \& Laurberg P. Frequent occurrence of pituitary apoplexy in patients with non-functioning pituitary adenoma. Clinical Endocrinology 200664 319-322. (doi:10. $1111 / \mathrm{j} .1365-2265.2006 .02463 . x)$

10 Dubuisson AS, Beckers A \& Stevenaert A. Classical pituitary tumour apoplexy: clinical features, management and outcomes in a series of 24 patients. Clinical Neurology and Neurosurgery 2007 109 63-70. (doi:10.1016/j.clineuro.2006.01.006)

11 Liu ZH, Chang CN, Pai PC, Wei KC, Jung SM, Chen NY \& Chuang CC. Clinical features and surgical outcome of clinical and subclinical pituitary apoplexy. Journal of Clinical Neuroscience 201017 694-699. (doi:10.1016/j.jocn.2009.11.012)

12 Biousse V, Newman NJ \& Oyesiku NM. Precipitating factors in pituitary apoplexy. Journal of Neurology, Neurosurgery, and Psychiatry 200171 542-545. (doi:10.1136/jnnp.71.4.542)

13 McFadzean R \& Teasdale G. Pituitary apoplexy, In Pituitary Adenomas, pp 485-501. Eds A Landolt, M Vance \& P Reilly. New York, NY: Churchill Livingstone, 1996.

14 McNemar Q. Note on the sampling error of the difference between correlated proportions or percentages. Psychometrika 194712 153-157. (doi:10.1007/BF02295996)

15 Jeffcoate WJ \& Birch CR. Apoplexy in small pituitary tumours. Journal of Neurology, Neurosurgery, and Psychiatry 198649 1077-1078. (doi:10.1136/jnnp.49.9.1077)

16 Ayuk J, McGregor EJ, Mitchell RD \& Gittoes NJ. Acute management of pituitary apoplexy - surgery or conservative management? Clinical Endocrinology 200461 747-752. (doi:10.1111/j.13652265.2004.02162.x)

17 Cardoso ER \& Peterson EW. Pituitary apoplexy: a review. Neurosurgery 198414 363-373. (doi:10.1227/00006123-198403000-00021)
18 Bjerre P, Gyldensted C, Riishede J \& Lindholm J. The empty sella and pituitary adenomas. A theory on the causal relationship. Acta Neurologica Scandinavica 198266 82-92. (doi:10.1111/j.16000404.1982.tb03131.x)

19 McCabe CJ, Boelaert K, Tannahill LA, Heaney AP, Stratford AL, Khaira JS, Hussain S, Sheppard MC, Franklyn JA \& Gittoes NJ. Vascular endothelial growth factor, its receptor KDR/Flk-1, and pituitary tumor transforming gene in pituitary tumors. Journal of Clinical Endocrinology and Metabolism 200287 4238-4244. (doi:10.1210/jc.2002-020309)

20 Bao YJ, Li XG, Jing ZT, Ou SW, Wu AH \& Wang YJ. Pituitary apoplexy complicated with subarachnoid hemorrhage caused by incidentaloma following a head injury: case report. Chinese Medical Journal 2007120 2341-2343.

21 Lohrer P, Gloddek J, Hopfner U, Losa M, Uhl E, Pagotto U, Stalla GK \& Renner U. Vascular endothelial growth factor production and regulation in rodent and human pituitary tumor cells in vitro. Neuroendocrinology 200174 95-105. (doi:10.1159/000054675)

22 Onesti ST, Wisniewski T \& Post KD. Clinical versus subclinical pituitary apoplexy: presentation, surgical management, and outcome in 21 patients. Neurosurgery 199026 980-986. (doi:10.1097/00006123-199006000-00010)

23 Zayour DH, Selman WR \& Arafah BM. Extreme elevation of intrasellar pressure in patients with pituitary tumor apoplexy: relation to pituitary function. Journal of Clinical Endocrinology and Metabolism 200489 5649-5654. (doi:10.1210/jc.2004-0884)

24 Karaca Z, Tanriverdi F, Atmaca H, Gokce C, Elbuken G, Selcuklu A, Unluhizarci K \& Kelestimur F. Can basal cortisol measurement be an alternative to the insulin tolerance test in the assessment of the hypothalamic-pituitary-adrenal axis before and after pituitary surgery? European Journal of Endocrinology 2010163 377-382. (doi:10.1530/EJE-10-0229)

Received 29 September 2010

Accepted 6 October 2010 